
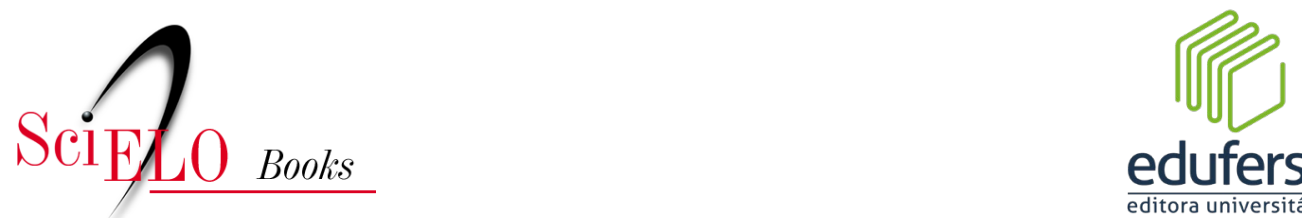

edufersa

editora universitária

\title{
14 - A festa do mangue na comunidade quilombola do Cumbe/CE: das suas histórias, valores culturais e lutas
}

\author{
Antônio Marcos dos Santos Souza \\ Gerciane Maria da Costa Oliveira \\ Kyara Maria de Almeida Vieira
}

\section{SciELO Books / SciELO Livros / SciELO Libros}

SOUZA, A. M. S., OLIVEIRA, G. M. C., and VIEIRA, K. M. A. A festa do mangue na comunidade quilombola do Cumbe/CE: das suas histórias, valores culturais e lutas. In: OLIVEIRA, G. M. C., and VIEIRA, K. M. A., eds. Patrimônio, povos do campo e memórias: diálogos com a cultura, a arte e a educação [online]. Mossoró: EdUFERSA, 2020, pp. 207-224. ISBN: 978-65-87108-09-4. https://doi.org/10.7476/9786587108605.0015.

\section{(c) (1)}

All the contents of this work, except where otherwise noted, is licensed under a Creative Commons Attribution 4.0 International license.

Todo o conteúdo deste trabalho, exceto quando houver ressalva, é publicado sob a licença Creative Commons Atribição 4.0. 


\title{
A FESTA DO MANGUE NA \\ COMUNIDADE QUILOMBOLA DO \\ CUMBE/CE: DAS SUAS HISTÓRIAS, \\ VALORES CULTURAIS E LUTAS
}

\author{
Antônio Marcos dos Santos Souza \\ Gerciane Maria da Costa Oliveira \\ Kyara Maria de Almeida Vieira
}

\section{Introdução}

Neste capítulo iremos tratar sobre o evento tradicional denominado Festa do Mangue que acontece anualmente na Comunidade Quilombola do Cumbe, Aracati-CE. De antemão, é de suma importância frisar que essa festa não se reduz a um evento descontextualizado e tampouco sem significados. Enquanto um acontecimento ${ }^{58}$, nos permite ir mais além na tentativa de discutir os valores culturais e a complexidade que envolve a Comunidade Quilombola do Cumbe.

Nosso nível de compromisso com este capítulo requer não apenas tratar sobre Festa do Mangue como se fosse algo isolado, mera diversão e sem fundamento, mas também colocar em questão a sua importância para a identidade local, os fatores que contribuíram e contribuem fortemente para a sua concretização.

58 Acontecimento aqui terá o sentido atribuído por Foucault (2000, p. 272-273):

"Acontecimento: é preciso entendê-lo não como uma decisão, um tratado, um reino ou uma batalha, mas como uma relação de forças que se inverte, um poder confiscado, um vocabulário retomado e voltado contra seus utilizadores, uma dominação que se enfraquece, se amplia e se envenena e uma outra que faz sua entrada, mascarada". 
Neste sentido, para uma melhor compreensão, falaremos sobre a Comunidade Quilombola do Cumbe e seus valores culturais. Em seguida, colocaremos em pauta os aspectos que compõem a emergência da Festa do Mangue. E, por último, iremos me deter sobre a Festa do Mangue trazendo algumas informações gerais do evento. Como procedimentos metodológicos da pesquisa, foram realizadas: i) pesquisa bibliográfica; ii) pesquisa de campo com a realização de entrevistas, e registro fotográfico. Para este capítulo, faremos o diálogo com referências bibliográficas e as fotografias.

Pensando na fotografia enquanto documento, é preciso considerar que "[...] toda fotografia assim como os acontecimentos que esta registra - ao contrário de apontarem para um passado inacessível - são potencialmente históricas e levam os sinais e rastros do seu tempo" (BORGES, 2007). Entretanto, como qualquer fonte histórica, a fotografia não é uma representação fiel dos fatos nem testemunham por si só o passado. Ao cristalizar um fragmento da realidade pretérita, uma pequena porção do mundo, "O papel da fotografia é conservar o traço do passado ou auxiliar as ciências em seu esforço para uma melhor apresentação da realidade do mundo" (DUBOIS, 2009, p. 30).

\section{A Comunidade Quilombola do Cumbe e seus patrimônios}

A comunidade Quilombola do Cumbe está situada no litoral leste do Ceará e estima-se que se componha de cerca de 105 famílias remanescentes de Quilombola.É impossível falar do Quilombo do Cumbe sem imergir no conjunto de bens culturais em suas duas dimensões (material e imaterial) ${ }^{59}$ que caracterizam a comunidade e se associam efetivamente às memórias sociais

59 De acordo com a Constituição Federal Brasileira (1988), em seu Art. 216, constituem patrimônio cultural brasileiro os bens de natureza material e imaterial, tomados individualmente ou em conjunto, portadores de referência à identidade, à ação, à memória dos diferentes grupos formadores da sociedade brasileira, quais sejam: a) As formas de expressão; b) Os modos de criar, fazer e viver; c) As criações científicas, artísticas e tecnológicas; d) As obras, objetos, documentos, edificações e demais espaços destinados às manifestações artístico-culturais; e) Os conjuntos urbanos e sítios de valor histórico, paisagístico, artístico, arqueológico, paleontológico, ecológico e científico. 
e aos traços identitários do povo quilombola do Cumbe. Vale ressaltar que "a identidade, então, costura [...] o sujeito à estrutura" (HALL, 2003, p.12), e as várias identidades que se pode assumir são, por vezes, contraditórias.

É em torno dessas percepções que os membros da Associação Quilombola desempenham suas atividades em favor da promoção de preservação de tudo aquilo que eles consideram patrimônio e que pode ser imprescindível para o bem viver, como para a manutenção da sua identidade e de sua vivência coletiva.

A Comunidade Quilombola do Cumbe certificada pela Fundação Cultural Palmares em dezembro de 2014, ficou conhecido no Ceará inteiro por produzir uma das melhores cachaças do estado e considerada a melhor da região. Era afamada a cachaça produzida nos engenhos e sítios do Cumbe. Porém, poucas informações e registros documentais encontraram sobre as pessoas que trabalhavam desde o preparo da terra a produção da cachaça (NASCIMENTO; LIMA, 2017, p. 6).

A comunidade Quilombola do Cumbe é contornada por belas praias e dunas brancas que no período de chuva fazem brotar em seus seios inúmeras lagoas de águas claras e que além da sua beleza natural, se configura em área de lazer que sempre despertou o interesse de seus habitantes e que hoje, consequentemente, vem despertando interesses também daqueles que não residem na comunidade.

Possui também um valor cultural, visto que, são paisagens que foram palcos de vidas e histórias das gerações passadas e que até hoje estão perpetuadas na memória dos moradores do território Quilombola do Cumbe ${ }^{60}$. São histórias passadas de geração em geração e que precisam ser conservadas. Uma dessas histórias consiste no Sebastianismo, mito messiânico que se originou através do desaparecimento do rei D. Sebastião na batalha

60 Pode-se também compreender as paisagens como um patrimônio rural, com efeito, “(...) sugere aquela transcrição a dificuldade de delimitação sobre o que deve ou não ser considerado patrimônio a preservar. Tal dificuldade coincide com o atual alastramento da noção de patrimônio a novas áreas, que ultrapassa a valorização específica do monumento e passa a integrar outros conjuntos, como centro histórico, patrimônio urbano e, mais recentemente, paisagens naturais (REIS, 1999 apud ALVES, 2004). 
de Alcácer Quibir e que seu povo tinha a esperança dele regressar e lutar contra toda miséria e sofrimento dos quais Portugal estava passando. Há muitos anos, as lavadeiras tinham o hábito de lavar suas roupas nas lagoas da comunidade e algumas delas conseguiam ouvir o som dos tambores da cavalaria e outras chegavam a ver até o próprio Rei Dom Sebastião.

Sobre as dunas do Cumbe também haviam os sambaquis composto por conchas, cacos de ostras e outros fragmentos que até poucos anos atrás eram expostos e colocados a serviço das aulas de campo que os professores realizavam com suas turmas, e que gerava uma aprendizagem significativa, porque além das aulas teóricas, estudantes tinham a oportunidade de ver e tocar nos fragmentos que constituíam os sambaquis e isso acabava estimulando estudantes a conhecer cada vez mais os primeiros nativos que habitaram na comunidade.

A Comunidade Quilombola do Cumbe também é contornada por rios e uma extensa área manguezal composto por uma diversidade de frutos que alimentam desde tempos longínquos os moradores e que ao mesmo tempo se traduz como fonte viável para a economia local, tendo em vista que os pescadores do Cumbe se alimentam do peixe, do caranguejo, da ostra, do sururu, da itã, dentre outros, ao passo que também os comercializam.

O rio e o ecossistema manguezal ${ }^{61}$ proporcionam também lazer, posto que as pessoas da comunidade se reúnem para diversão, esta que consiste na prática tradicional denominada como "comer no mato": alguns saem a barco para pescar e outros se dispõem das margens do rio sobre as sombras das árvores para se acomodarem e manter um bom entretenimento, como conversas despretensiosas, banho de rio e passeio de barcos durante o tempo que a outra turma está realizando a pesca e tudo que for pescado é preparado e saboreado no mesmo local, no mangue.

61 Manguezal é um ecossistema costeiro, de transição entre os ambientes terrestre e marinho, característico de regiões tropicais e subtropicais, sujeito ao regime das marés. É constituído de espécies vegetais lenhosas típicas (angiospermas), além de micro e macroalgas (criptógamas), adaptadas à flutuação de salinidade e caracterizadas por colonizarem sedimentos predominantemente lodosos, com baixos teores de oxigênio. Ocorre em regiões costeiras abrigadas e apresenta condições propícias para alimentação, proteção e reprodução de muitas espécies animais (SCHAEFFERNOVELLI, 1995 apud SANTOS, 2009). 
Figura 1 - O rio Jaguaribe, na Comunidade Quilombola do Cumbe

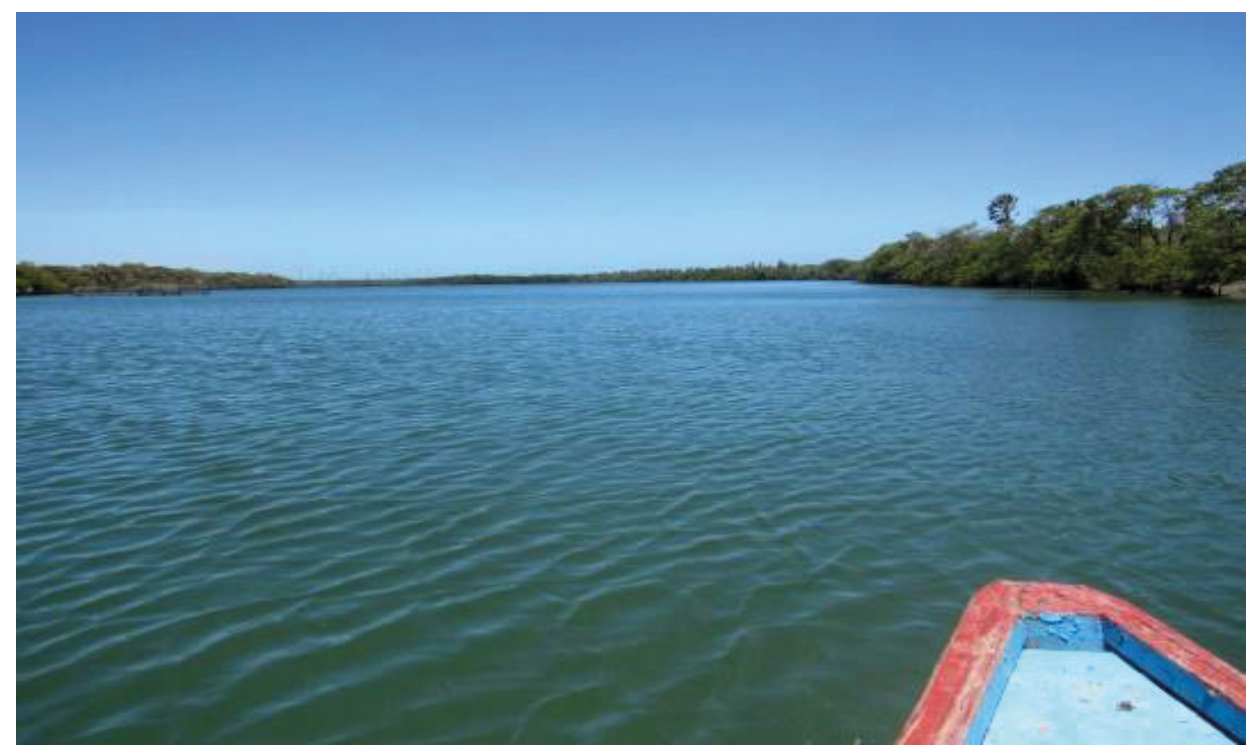

Fonte: Autoria própria (2019).

Figura 2 - Braço do Rio Jaguaribe; ecossistema manguezal do Quilombo do Cumbe

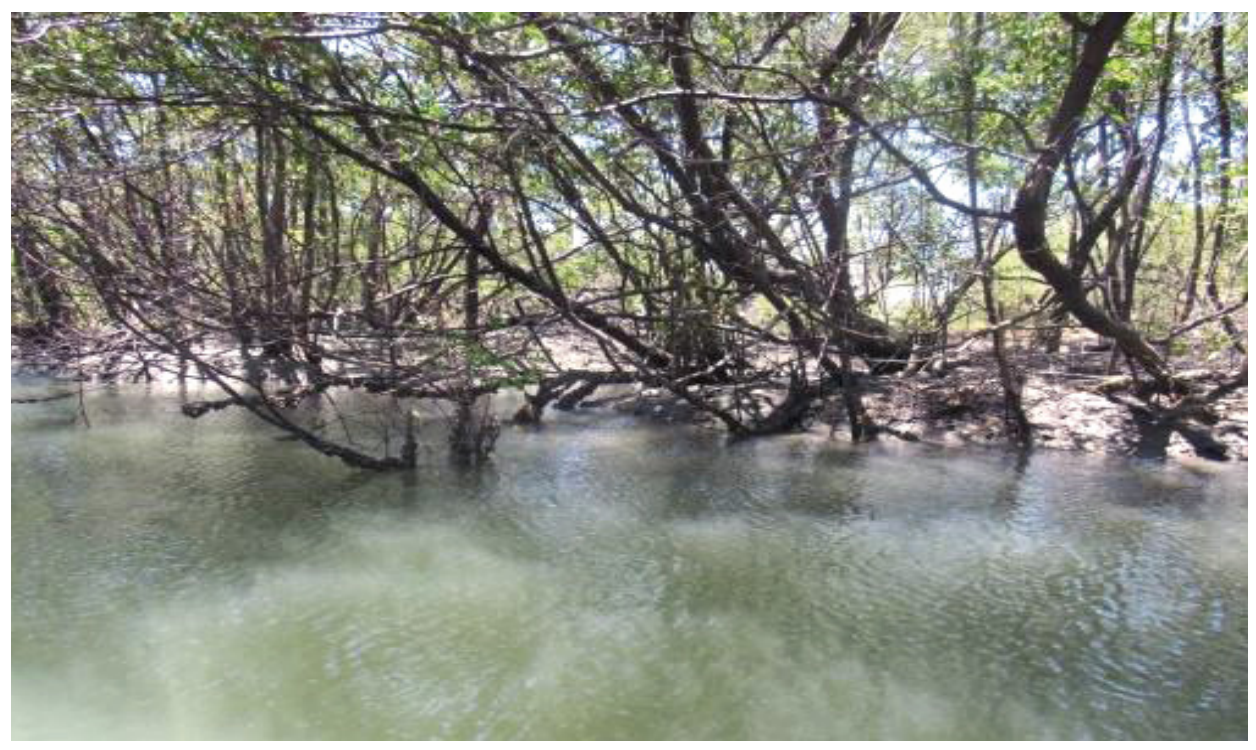

Fonte: Autoria própria (2019). 
A economia da Comunidade Quilombola do Cumbe também gira em torno do artesanato: algumas pessoas artesãs/os produzem uma diversidade de objetos muito bem trabalhado e se usam das matérias primas do próprio lugar como o coco, o talo, a madeira, o barro e outros, para dar existência a obras que são comercializadas e as vezes colocadas em exposição nas feiras culturais que acontecem no município de Aracati; já outras pessoas produzem roupas e toalhas de labirintos, é um saber fazer que exige das labirinteiras muita sabedoria e muita paciência e é o que torna o produto final muito valorizado, a atividade do labirinto também é um saber fazer tradicional herdado de outras gerações. Tais objetos artesanais, além de ser comercializadas na própria comunidade do Cumbe, são também expostos nas feiras culturais que envolvem também a gastronomia, festivais de músicas, teatros e outros.

Figura 3 - Obras artesanais expostas na Festa do Mangue

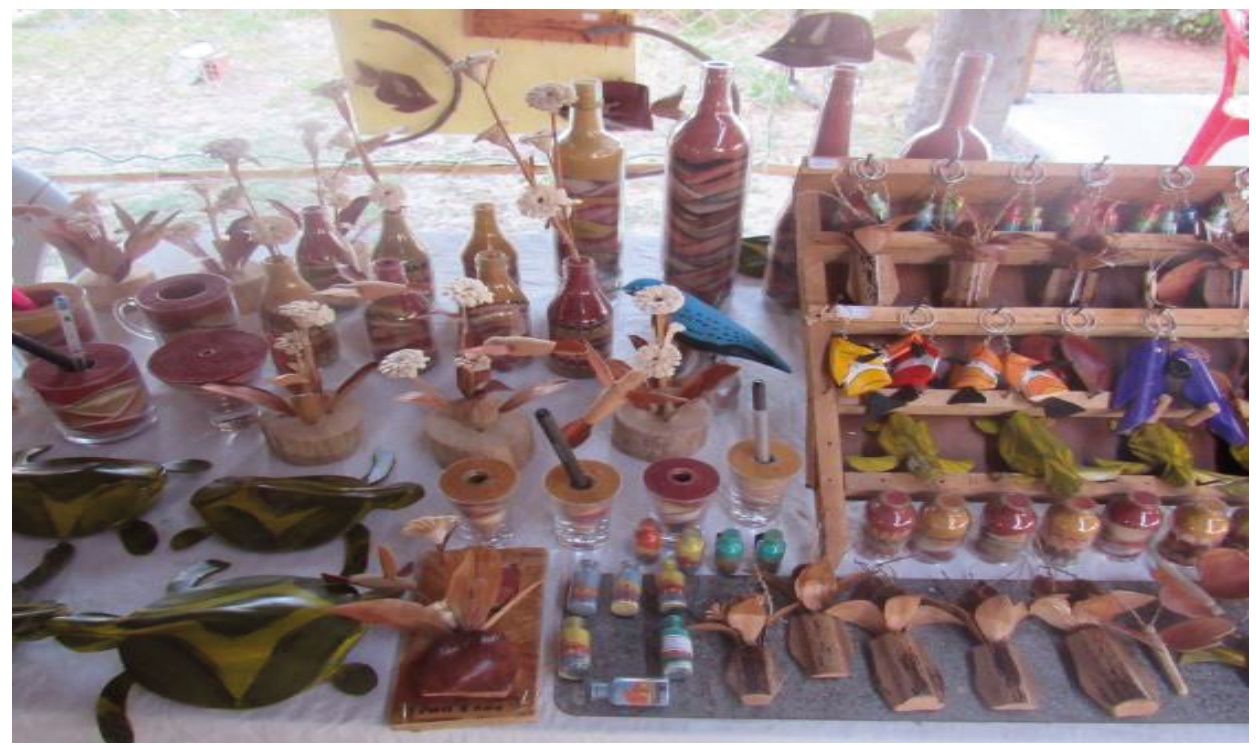

Fonte: autoria própria (2019). 
Figura 4-Bolsas artesanais feitas através da palha

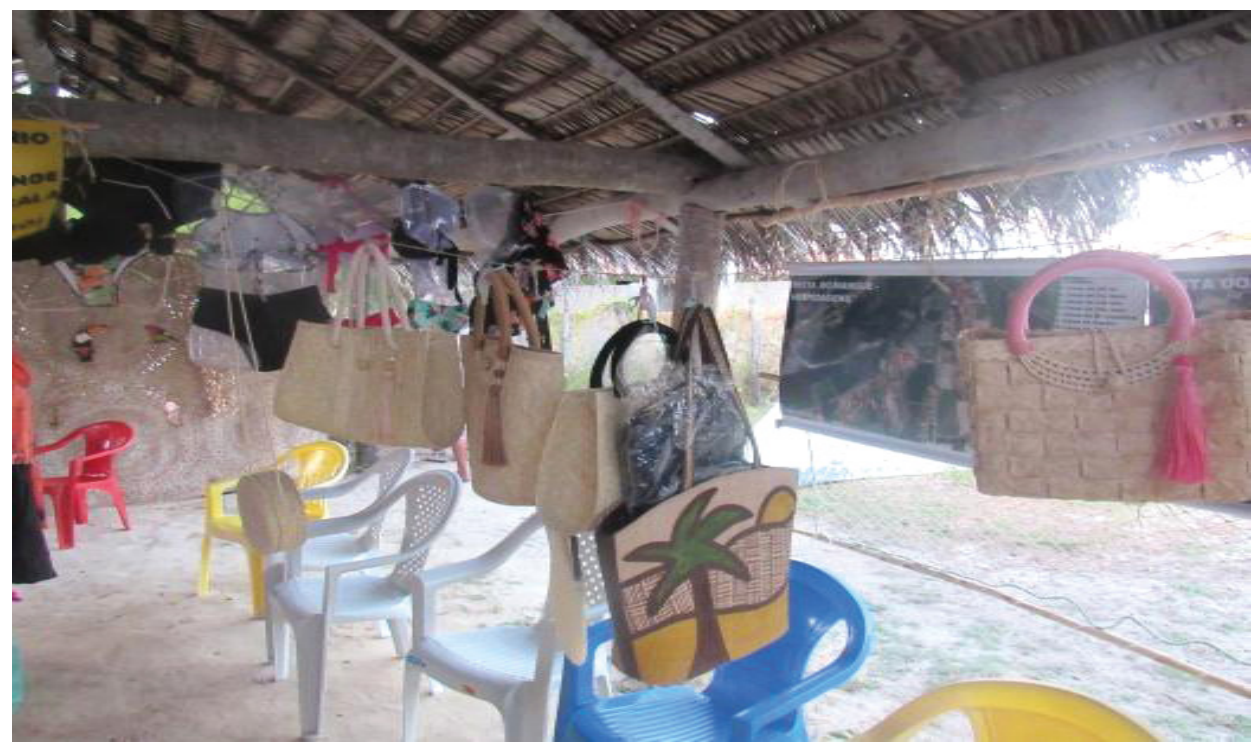

Fonte: autoria própria (2019).

Essa variedade de bens culturais é significativa para o povo da Comunidade Quilombola do Cumbe e seria difícil as pessoas viverem sem esses bens culturais e é com base nisso que vai se fortalecendo, cada vez mais, a relação afetiva dos moradores com áreas agricultáveis e ambientais, ou seja, com esse conjunto de bens que proporcionam uma melhor qualidade de vida; é a partir daí que os membros da associação Quilombola do Cumbe reconhecem a necessidade de preservar e conscientizar os outros moradores a zelar também por essas riquezas que têm em volta do/ no Quilombo do Cumbe.

Os patrimônios culturais materiais e imateriais não são dissociáveis; sua integração se dá pela relação entre si e pelo sentido que lhes é atribuído pelas pessoas da comunidade: o mangue e os rios, por exemplo, são imprescindíveis para a manutenção da identidade pesqueira, visto que são nessas áreas em que os pescadores do Cumbe realizam as suas atividades tradicionais como as diversas formas de pesca (peixes, crustáceos e mariscos) que oportuniza o sustento para os/as moradores ao mesmo tempo em que possibilita criar e dar nome a sua própria culinária, tendo como base produtos alimentícios do próprio lugar. 
O patrimônio cultural de uma sociedade é também fruto de uma escolha, que, no caso das políticas públicas, tem a participação do Estado por meio de leis, instituições e políticas específicas. Essa escolha é feita a partir daquilo que as pessoas consideram ser mais importante, mais representativo da sua identidade, da sua história, da sua cultura (IPHAN, 2012, p. 14).

A culinária compreende desde o modo de fazer, os sabores até a origem dos alimentos, e isso se traduz também em patrimônio da Comunidade Quilombola do Cumbe: não falta uma boa caranguejada, o sururu no leite de coco, a moqueca de arraia e etc., que são pratos que chamam atenção em decorrência dos seus sabores inigualáveis.

Compreende-se a partir daí que o homem se constrói a partir desses bens culturais, como as crenças, as festas tradicionais, as histórias e o modo de ser, que se interligam aos bens paisagísticos e aos bens arquitetônicos. Sobre este último há o exemplo próximo a Comunidade Quilombola do Cumbe, que tem uma escola simples e antiga e que parou de funcionar há mais de duas décadas. Para algumas pessoas talvez pareça simples, mas quando um morador da comunidade olhar para essa escola, possivelmente vai sentir um turbilhão de sentimentos, vai se emocionar e estimular memórias do passado e essa conexão do morador com essa escola vai se converter em patrimônio, porque além da transição do passado para o presente, essa escola é testemunha de uma história e de um passado que marcam a vida daquelas pessoas que lá estudaram. "Ou seja, são os valores, os significados atribuídos pelas pessoas a objetos, lugares ou práticas culturais que os tornam patrimônio de uma coletividade (ou patrimônio coletivo)" (IPHAN, 2012, p. 14).

E ainda esses bens culturais e naturais por serem convertidos em patrimônios rurais podem também fazer conexão com outras atividades economicamente viáveis e assim proporcionar oportunidade de desenvolvimento local. É o que acontece na Comunidade Quilombola do Cumbe, em que os membros da Associação Quilombola desenvolvem o turismo comunitário. Neste sentido, "Um aspecto importante a ser considerado na perspectiva de troca de conhecimento e valores decorrente do encontro entre 'nativos' e turistas é o resgate dos costumes e das festas tradicionais realizadas pela 
comunidade local" (RODRIGUES, 2012, p. 239). Desta forma, o Quilombo do Cumbe, como outras comunidades, fazem parceria com a Rede Tucum ${ }^{62}$, para a qual cada comunidade repassa uma determinada porcentagem do lucro obtido pelo turismo comunitário para a Rede Tucum, e esta faz a divulgação e a organização para a comunidade receber o turismo. Todos os anos tem a assembleia com a Rede Tucum para discutir os rumos do turismo nas comunidades nos anos seguintes.

\section{Luta e resistência em defesa dos patrimônios rurais e da identidade local}

O que aconteceria se o povo da Comunidade Quilombola não tivesse a noção do quão importante é sua identidade? E se não refletisse sobre os problemas recorrentes enfrentados pela comunidade? A resposta para essas perguntas é que não haveria resistência e nem luta contra tudo aquilo que viesse comprometer drasticamente a sua realidade local. Para resistir é necessário que haja antes uma capacidade reflexiva e crítica sobre o estado das coisas. E aqui

O local não deve ser compreendido apenas como o espaço em que se realizam as práticas diárias, mas também como aquele no qual se situam as transformações e as reproduções das relações sociais de longo prazo, bem como a construção física e material da vida em sociedade. Nele, realiza-se o cotidiano, o momento, o fugidio, mas também a história, o permanente, o fixo, correspondendo ao identitário, ao relacional e ao histórico, no âmbito da tríade habitante-identidade-lugar (ALBAGLI, 2004 apud LAGES; BRAGA; MORELLI, 2004, p. 51).

62 A rede Cearense de Turismo Comunitário (Rede Tucum) começou a existir formalmente apenas em 2008, mas surge para reforçar a articulação e potencializar uma luta que já tem vários capítulos: a defesa dos territórios e dos modos de vida dos povos tradicionais da Zona Costeira do Ceará. A partir de uma concepção de turismo ambientalmente e socialmente justos, no qual as pessoas das próprias comunidades protagonizam a atividade, a Rede Tucum intenta contribuir na afirmação, ocupação e a apropriação dos territórios, lançar novos olhares sobre o que já era conhecido e interagir com os demais sistemas produtivos locais" (INSTITUTO TERRAMAR, 2017, p. 6). 
É comum os grandes empresários, donos de latifúndios, invadirem comunidades e, ao mesmo tempo, promoverem a marginalização das experiências da comunidade, construindo um imaginário negativo sobre o território invadido, visando facilitar a aceitação passiva da invasão, e assim descaracterizar, isolar e simplificar uma diversidade cultural que constrói e dá sentido à realidade dos moradores. "Toda invasão sugere, obviamente, um sujeito que invade seu espaço histórico cultural, que lhe dá sua visão de mundo, é o espaço de onde ele parte para penetrar outro espaço histórico-cultural, superpondo aos indivíduos deste seu sistema de valores" (FREIRE, 1985, p. 26).

Em 1996, os moradores do Cumbe foram surpreendidos com a chegada da carcinicultura. Os empresários dos empreendimentos de camarões, na medida que se instalavam na comunidade, alimentavam o discurso de progresso para ganhar a confiança dos nativos da Comunidade Quilombola do Cumbe. Na prática, ocorreu a privatização de áreas que antes eram de livre acesso; a destruição das áreas manguezais para a construção de viveiros; e a poluição dos rios, visto que, o manejo adotado nessas atividades econômicas não funciona de modo sustentável, ou seja, eles abastecem os seus viveiros com as águas do rio e durante o processo de cultivo usam produtos químicos. Essa mesma água contaminada, ao invés de ser jogada em um reservatório para ser tratada, simplesmente retorna para o rio, promovendo assim a sua poluição.

Desta forma, a Comunidade Quilombola do Cumbe, como parte de uma dinâmica econômica em seus primórdios, durante muitos anos teve papel importante como produtora de cana-de-açúcar, cachaça, rapadura, coco, manga, banana, algodão, farinha, cera de carnaúba, mel, sal, leite, sabão, velas, peixes e mariscos, na atualidade se depara com a invasão do seu território por empreendimentos econômicos incompatíveis com as práticas tradicionais e responsáveis pela desorganização das práticas culturais (NASCIMENTO; LIMA, 2017, p. 2).

É diante desses problemas que os membros da Associação Quilombola do Cumbe tomam a linha de frente para resistir e lutar de forma justa contra a instalação desses empreendimentos que colocavam em risco a cultura, 
a identidade local, o meio ambiente e o modo de vida dos/as moradores. Nesta dinâmica instalou-se um conflito interno e permanente enfrentado por membros da Associação Quilombola que vêm resistindo em defesa do território, dos bens culturais, da identidade local, etc. Essa luta vem acontecendo há mais de uma década e encontra enfrentamentos dentro da própria comunidade, pois algumas pessoas assumem/ apoiam o discurso desses empreendimentos.

Recentemente os moradores do Cumbe foram surpreendidos mais uma vez pelo avanço do capital mediante a chegada dos Parques Eólicos. Nas contradições do discurso da "energia limpa", o aproveitamento dos ventos para geração de energia apresenta, como outras tecnologias energéticas, impactos ambientais desfavoráveis como: morte de aves, impacto visual, poluição sonora, interferência eletromagnética, mudanças no clima local e regional, aumento do efeito estufa, danos à fauna, desmatamento e a erosão do solo; escavação, fundação e construção de estradas na construção de um parque eólico podem afetar também o bio-sistema local (AZEVEDO; NASCIMENTO; SCHRAM, 2016).

Na Comunidade Quilombola do Cumbe, em termos práticos, os cata-ventos e as fiações de energia ao serem instaladas sob as dunas ocuparam e privatizaram as grandes áreas que eram livres para moradores/as, tornando-as limitadas, restringindo assim o direito que as pessoas tinham de transitar por toda parte das dunas sem sofrer nem um tipo de interdição.

Neste processo, algumas lagoas também foram aterradas, inclusive aquelas que eram mais frequentadas pelos moradores. Aterraram também os sambaquis que registravam a história das gerações passadas e durante esse tempo das implantações dos cata-ventos da energia eólica, foram encontradas 41 mil peças antigas pelas dunas do Quilombo do Cumbe e que, por falta de um museu na comunidade, a maior parte desses fragmentos foram levados para o museu Câmara Cascudo em Natal-RN e a menor parte foi para o Instituto Tembetá- Arqueologia e Preservação em Fortaleza-CE. Com a fundação do Museu Comunitário do Cumbe, em 2019, parte desses artefatos foram recuperados. 


\section{Festa do Mangue}

Foi em decorrência desse conflito interno que os membros da Associação Quilombola sem uniram e decidiram criar a Festa do Mangue para se reinventarem e darem visibilidade à sua luta pela reafirmação de suas práticas, costumes, memórias e toda uma cultura que precisa ser viabilizada e valorizada. Essa festa simboliza a resistência e a luta justa contra as ameaças do agronegócio vigente que descaracteriza toda dinâmica social e que devasta o meio ambiente.

A Festa do Mangue é um evento tradicional realizado anualmente no território Quilombola do Cumbe/Ceará. A última edição ocorreu entre os dias 18, 19 e 20 de outubro de 2019 e confirmou a dinâmica das edições anteriores ao contar não somente com a presença de moradores/as, mas também com um público diverso de outras localidades, o que permite uma experiência de partilha de saberes, de modos de viver, de práticas culturais. Se para Canclini (2008) a cultura é um fenômeno que mediante símbolos e representações auxiliam na reprodução ou transformação do sistema social, a cultura, portanto, é um processo de produção de significados, estes que são capazes de manter ou modificar maneiras de viver, ideias e valores.

Figura 5-Palestra na Festa do Mangue com o historiador João do Cumbe sobre a história da Comunidade Quilombola do Cumbe

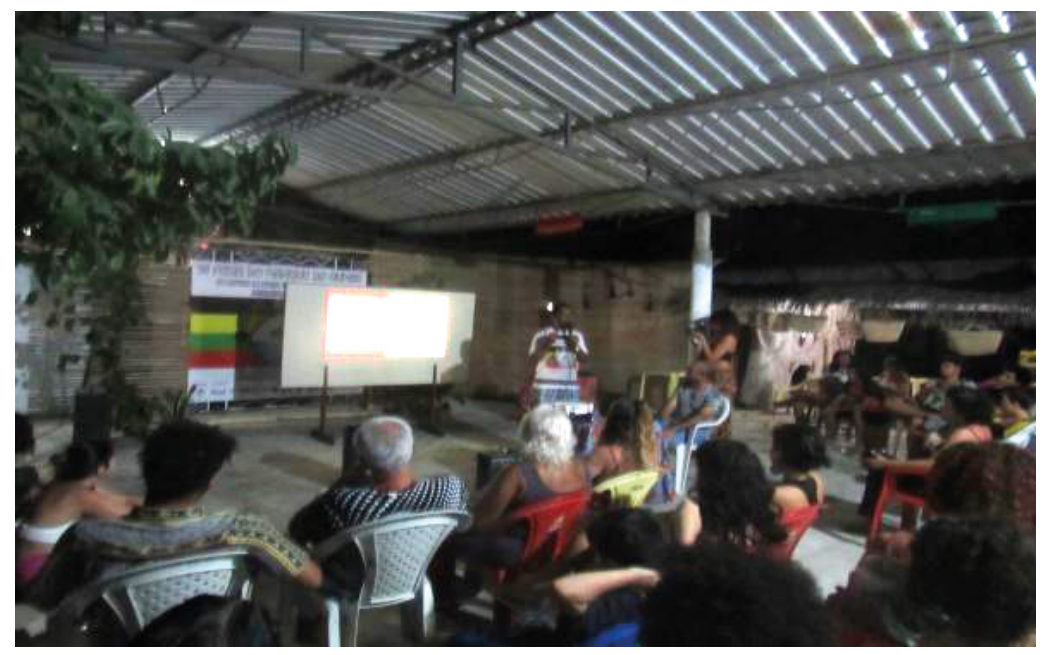

Fonte: Autoria própria (2019). 
A Festa do Mangue foi construída pela diretoria da Associação Quilombola do Cumbe e teve início no ano de 2014. Da primeira até a sexta edição, a Festa do Mangue tem um aumento significativo da frequência do público, indo de 30 para 500 pessoas. Um dos motivos desse aumento deve-se ao fato das várias edições da Festa do Mangue serem divulgadas tanto pelos moradores como pelas pessoas que vêm de fora para prestigiá-la e que divulgam através das redes sociais, como pelo facebook, instagram, twitter e por outros meios de comunicação.

As pessoas que vêm de fora são bem recepcionadas e acolhidas nas casas dos moradores para passar os três dias do evento, e suas inscrições se dão por um valor acessível, o que garante a participação nas atividades e o direito às refeições que compreendem o café da manhã, o almoço e o jantar.

Na medida em que a Festa do Mangue proporciona para os seus inscritos o lazer, a diversão, a culinária regional, conhecimento e toda diversidade cultural, ela vai se traduzindo em fonte viável para a economia local, pois os moradores usam o espaço onde acontecem as atividades e que concentram o público para realizar feiras e assim comercializar as suas obras artesanais e suas comidas típicas, estes que tem tido uma forte aceitação e apreciação pelo público participante.

A partir do momento que cultura e consumo são tratados conjuntamente, o consumo deixa de ser um simples produzir, comprar e usar objetos para se tornar um sistema simbólico, através do qual a cultura manifesta seus princípios, categorias, ideais, valores, identidades e projetos (ROCHA, 2000 apud FAGIANNI, 2006, p. 24).

A Festa do Mangue tem uma programação de atividades a serem realizadas durante os três dias. Dentre essas atividades tem o passeio pela comunidade, a visita pelos sítios arqueológicos para as pessoas conhecerem as histórias das gerações passadas, a trilha pelas dunas do Cumbe que envolve também um momento de socialização e dinâmicas culturais das quais todos participam, e finaliza com a contemplação do pôr do sol.

Ocorrem também nesses dias as oficinas das várias formas de pesca do peixe, do sururu, da ostra, do búzio e outros, nas quais o público participante da festa tem a chance de conhecer e ao mesmo tempo praticar essas 
atividades. Fica a critério do público a escolha pela modalidade de pesca. A atividade se encerra com a tradição do "comer no mato", na qual tudo que foi pescado durante a oficina é preparado e saboreado na beira do rio.

Figura 6-O porto do rio Jaguaribe onde é feita concentração das pessoas para iniciar as oficinas de pesca pelo rio Jaguaribe

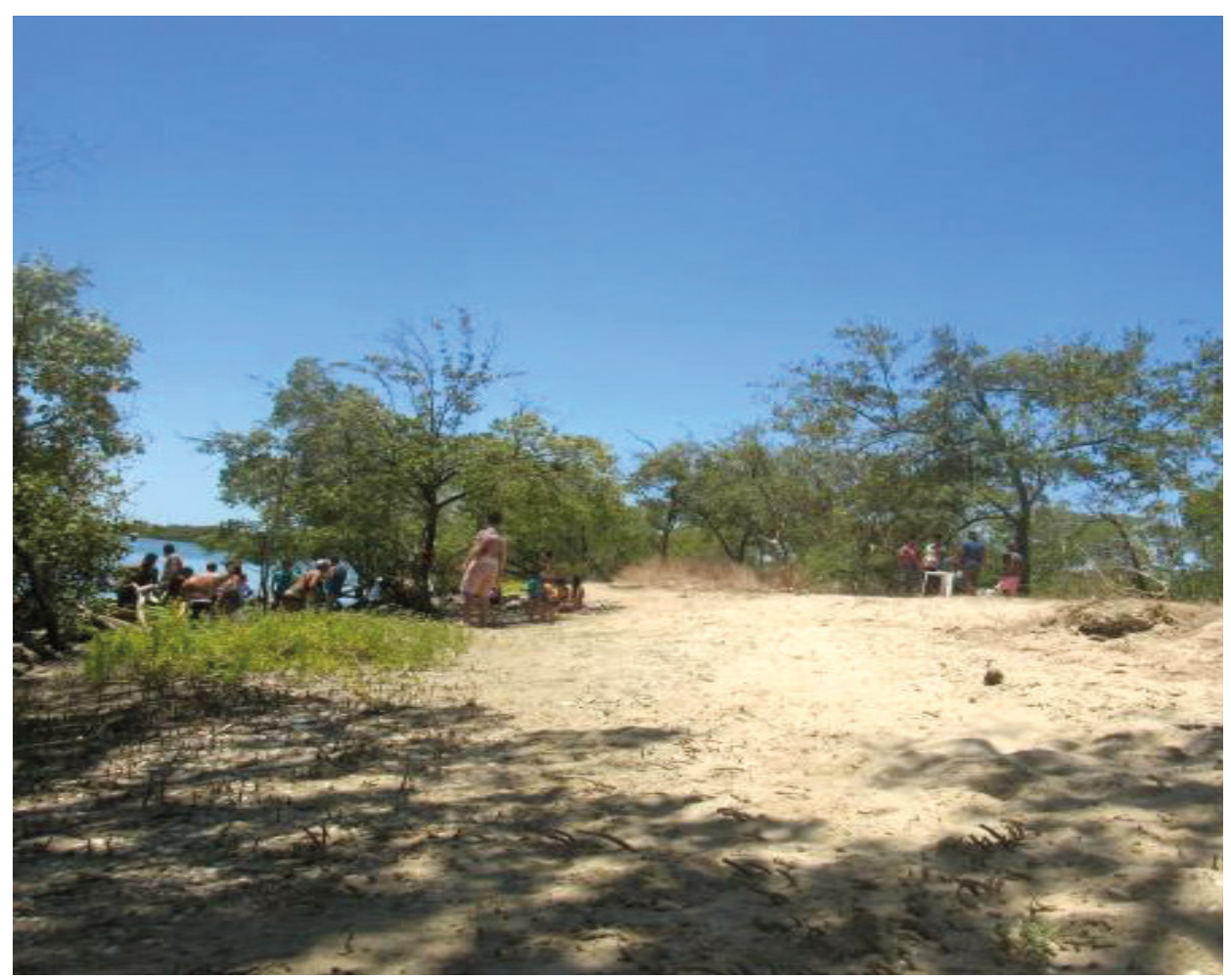

Fonte: Autoria própria (2019). 
Figura 7-Momento de socialização depois da trilha realizada nas dunas da Comunidade Quilombola do Cumbe

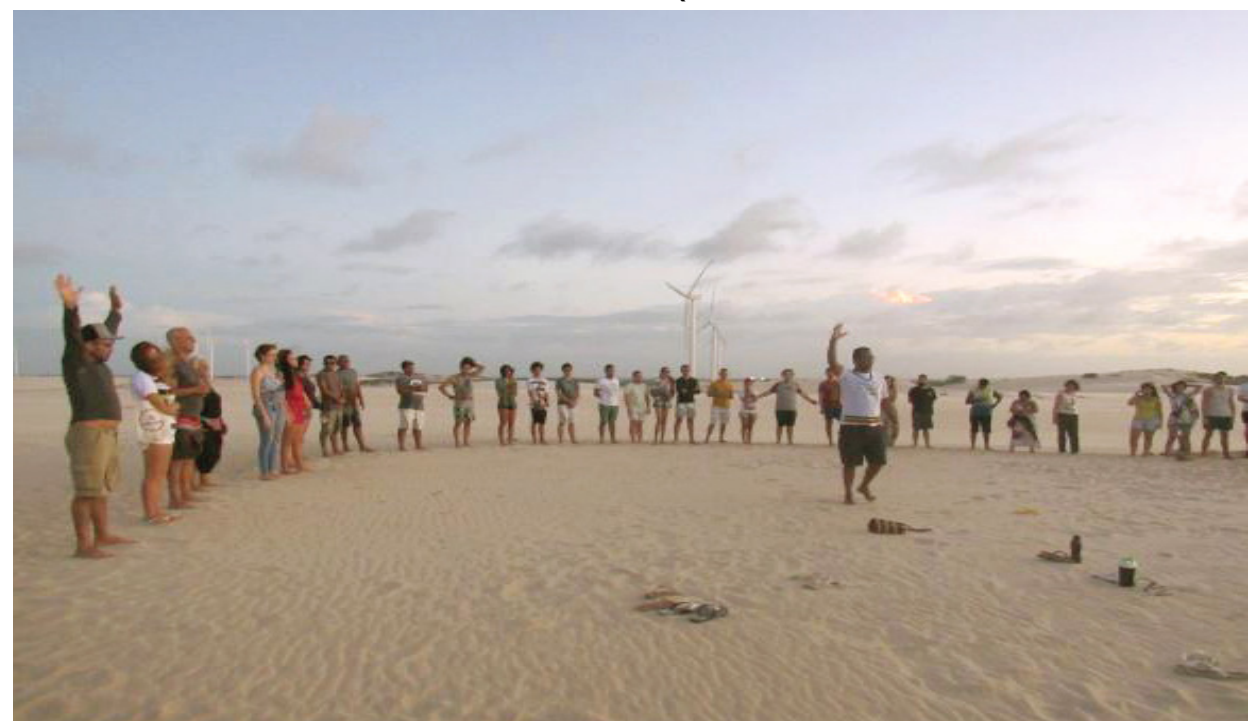

Fonte: Autoria própria (2019).

Figura 8-A trilha pelas dunas da Comunidade Quilombola do Cumbe

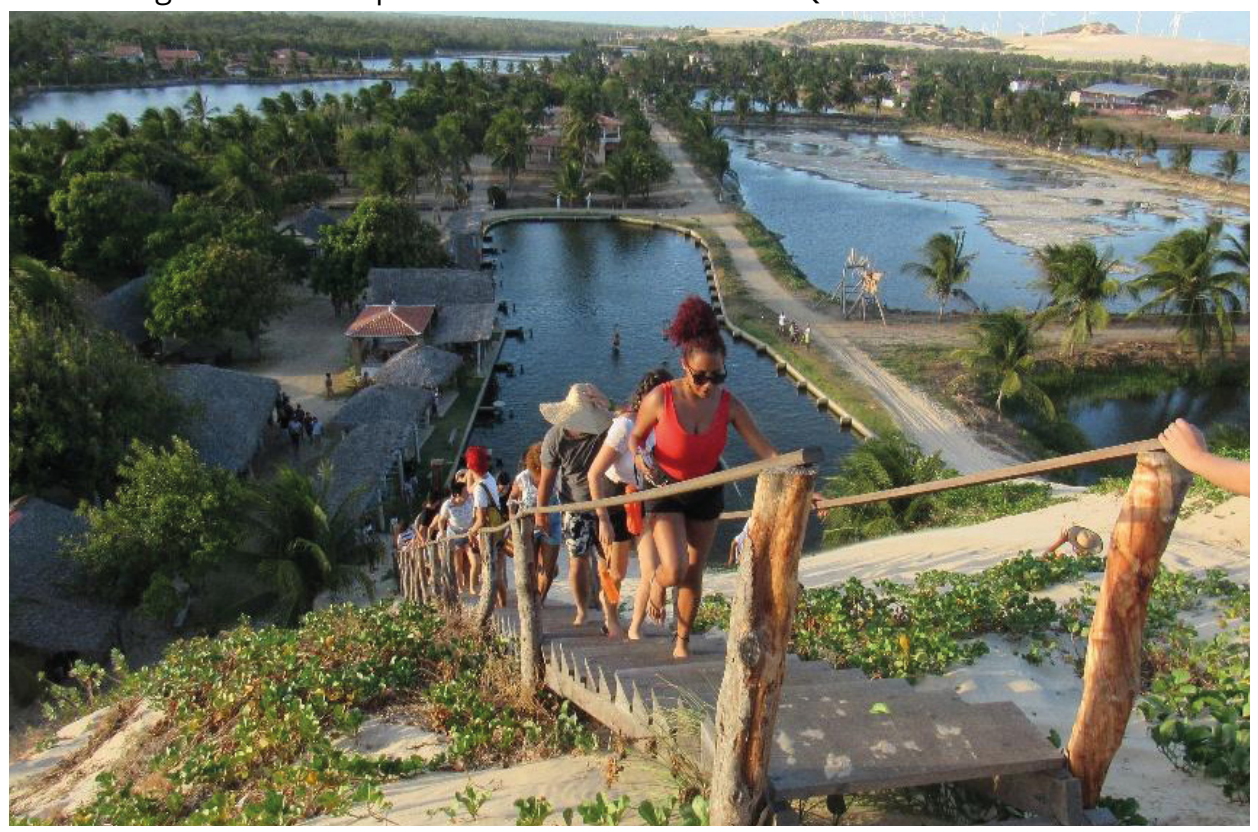

Fonte: Autoria própria (2019). 
Como mais uma atividade, as pessoas acompanham os pescadores que saem pelo mangue para uma disputa de captura do maior número de caranguejo. Por uma solicitação das crianças da comunidade, a disputa acontece entre homens adultos, e outra disputa entre crianças. $\mathrm{O}$ vencedor desta atividade ganha um prêmio em dinheiro.

$\mathrm{Na}$ programação existem vários momentos culturais, como as apresentações de calungas, as rodas de capoeira, a dança do coco, a apresentação do maracatu, os forrós pé de serra, palestras, as homenagens aos mestres e mestras quilombolas pescadores e as pessoas que estão engajadas com a luta que vem sendo travada na comunidade. Tem também campeonato de futebol, rodas de conversa sobre a história da Comunidade Quilombola do Cumbe.

Finalmente, podemos perceber com base neste capítulo, a importância de preservar os patrimônios rurais, as memórias coletivas e os bens culturais e naturais na reafirmação da identidade local. Vimos também os embates que a Comunidade Quilombola do Cumbe vem travando em defesa desses patrimônios, na busca pela promoção do bem viver e da sustentabilidade econômica e social. Enfocou-se ainda a Festa do Mangue como um evento de expressão cultural no qual as memórias, histórias, fazeres e práticas próprias da comunidade são reafirmadas entre seus moradores e compartilhadas com o público visitante. 


\section{REFERÊNCIAS}

ALVES, J. E. Sobre o patrimônio rural: contributos para a clarificação de um conceito. Cidades Comunidades e Territórios, v. 8, p. 32-52, 2004.

AZEVEDO, J. P. M.; NASCIMENTO, R. S.; SCHRAM, I. B. Energia eólica e impactos ambientais: um estudo de revisão. [S.l.:s.n.], 2016. Disponível em: https://bit.ly/2GTrLta. Acesso em: 11 fev. 2020.

BORGES, P. Humberto Porto: História e fotografia. [S.l.:s.n.], 2007. Disponível em: https://bit.ly/3iAlXmo. Acesso em: 22 abr. 2020.

BRASIL. [Constituição Federal (1988)]. Constituição da República Federativa do Brasil. Diário Oficial da União. Brasília, 5 out. 1988. Disponível em: https://bit.ly/3bXSNLn. Acesso em: 14 set. 2020.

CANCLINI, N. G. Culturas híbridas. 4. ed. São Paulo: EdUSP, 2008.

DUBOIS, P. 0 Ato fotográfico e outros ensaios.

Campinas, Papirus, 1994.

FAGIANNI, K. O Poder do design. Brasília: Thesaurus, 2006 FOUCAULT, M. Arqueologia das Ciências e História dos sistemas de pensamento. In: Manoel Barros Motta (org.). Rio de janeiro: Forense-Universitária, 2000. (Ditos \& Escritos, v. 2). FREIRE, P. Extensão ou comunicação? 8. ed. Rio de Janeiro: Paz e Terra, 1985. 
HALL, S. A Identidade cultural na pós-modernidade. Tradução de Tomaz Tadeu da Silva e Guacira Lopes Louro. 7. ed. Rio de Janeiro: DP\&A, 2003.

IPHAN-INSTITUTO DO PATRIMÔNIO HISTÓRICO E ARTÍSTICO NACIONAL. Patrimônio cultural imaterial: para saber mais. 3. ed. Brasília: IPHAN, 2012.

INSTITUTO TERRAMAR. Rede Tucum: das ondas do mar aos quintais da vida. [S.l.]: Instituto Terramar, 2017.

LAGES, V.; BRAGA, C.; MORELLI, G. (org). Territórios em movimento: cultura e identidade como estratégias de inserção competitiva. Rio de Janeiro: Relume Dumará; Brasília: SEBRAE, 2004.

NASCIMENTO, J. L. J.; LIMA, I. C. Nas trilhas da memória e da história: cumbe um museu a céu aberto. In: ENCONTRO REGIONAL NORDESTE DE HISTÓRIA ORAL, 11., 2017, Fortaleza. Anais [...]. Fortaleza: UFC, 2017. Disponível em: https://bit.ly/3hzZioN. Acesso em: 14 set. 2020.

RODRIGUES, C. G. O. O Turismo e a reconstrução do espaço rural. In: CARNEIRO, M. J. Ruralidades contemporâneas: modos de viver e pensar o rural na sociedade brasileira. Rio de Janeiro: FAPERJ, 2012.

SANTOS, A. L. G. Manguezais da Baixada Santista-SP: alterações e permanências (1962-2009). 2009. 169 f. Dissertação (Mestrado em Ciência Ambiental)-Universidade de São Paulo. São Paulo, 2009.

VAN DEN BESSELAAR, J. O Sebastianismo: história sumária. Lisboa: Bertrand, 1987. 